\title{
Bullous pemphigoid appearing as superficial tissue necrosis after irradiation of the breast: Case history and definitive review of the literature
}

\author{
Mark Trombetta ${ }^{1,4}$, Kathleen Erb' ${ }^{2,4}$, Vijay Kudithipudi ${ }^{1}$, J udith Small ${ }^{3,4}$ \\ 1. Department of Radiation Oncology, Allegheny General Hospital, Pittsburgh, United States. 2. Department of Surgery, \\ Allegheny General Hospital, Pittsburgh, United States. 3. Division of Dermatology, Allegheny General Hospital, Pittsburgh, \\ United States. 4. Temple University School of Medicine, Pittsburgh Campus, Pittsburgh, United States.
}

Correspondence: Mark Trombetta, M.D. Address: Department of Radiation Oncology, Allegheny General Hospital, 320 East North Ave., Pittsburgh, PA 15212, United States. Email: mtrombet@wpahs.org

Received: May 4, 2015

Accepted: May 27, 2015

Online Published: June 3, 2015

DOI : $10.5430 /$ jst.v5n2p53

URL: http://dx.doi.org/10.5430/jst.v5n2p53

\begin{abstract}
Bullous pemphigoid is an unusual condition that occurs rarely as a complication following radiotherapy. Because of the difficulties in the diagnosis of this disease and the need for raising awareness of such as a complication of therapeutic intervention we present a case report and review of the literature with discussion to highlight this disease which can confound the management of breast cancer.
\end{abstract}

\section{Key words}

Radiation, Bullous pemphigoid, Breast cancer, Necrosis, Skin

\section{Case presentation}

A 73-year-old fair-skinned Caucasian female presented for a routine screening mammogram in July of 2012 which demonstrated a suspicious $1.0 \mathrm{~cm}$ spiculated solid density in the central region of the left breast. The Breast Imaging Reporting and Data System (BI-RADS) category was assessed as 4. Immediately following the mammogram, the patient underwent a core needle biopsy under stereotactic guidance which revealed a moderately differentiated estrogen and progesterone positive invasive ductal carcinoma. Her 2 neu was not overexpressed and the Ki 67 ratio was $22 \%$. The patient underwent a left sided needle localized lumpectomy and sentinel node biopsy. The final pathology demonstrated a $0.8 \mathrm{~cm}$ lesion downgraded to low grade differentiation with negative resection margins. In addition, a small component of ductal carcinoma in-situ was identified in the specimen. No comedonecrosis was identified. The final margins of resection were clear with greater than $0.2 \mathrm{~cm}$ circumferentially uninvolved. None of the three sentinel lymph nodes was positive for malignancy. A metastatic work up including a comprehensive metabolic panel, a chest x-ray and routine hematologic indices was within normal limits. Her physical exam demonstrated no abnormalities. The patient had a past medical history significant for essential hypertension, fibrocystic breast change, gastro-esophageal reflux, osteoporosis and benign ovarian cysts. She had no appreciable family history of cancer and used hydrochlorothiazide, esomeprazole, and amlodipine. She was allergic to penicillin, sulfa compounds and codeine. She received $4256 \mathrm{cGy}$ at $266 \mathrm{cGy}$ per fraction to the right breast, completing such in October of the same year. During radiotherapy, the patient developed grade I erythema 
as determined by the Common Terminology Criteria for Adverse Events (CTCAE; v 4.03) ${ }^{[1]}$ which resolved within one week post irradiation. Following this, she began a course of anastrazole; $1.0 \mathrm{mg}$ daily. In December of the same year, she developed tenderness and erythema in the breast near the areola, which spread to the supra-areolar region. This was treated topically with aloe vera which led to slight improvement; however, the lesion soon began to exude a yellowish purulence. The patient was afebrile at that time. A two-week course of amoxicillin with clavulinic acid $875 \mathrm{mg} / 125 \mathrm{mg}$ was begun with minimal improvement. The lesion progressed to involve the entire superior half of the breast and there was a suspicion of a fluid collection under the skin. The patient's perceived pain rose to a level of 8/10. Narcotics were used to control her pain. A breast ultrasound confirmed a very small sub-dermal fluid collection. Aspiration of the fluid was performed. Cytology and culture was unremarkable with no bacteria and scant red blood cells. She was referred to another breast surgeon for a second opinion and then to a dermatologist. Upon examination by dermatology, patchy erythematous intact bullae affecting the right breast were noted which included the entire superficial nipple-areolar complex. The patient underwent skin biopsy which demonstrated sub-epidermal vesiculobullous dermatitis with eosinophils and neutrophils in abundance consistent with bullous pemphigoid. Direct immunofluorescence of the peri-lesional skin was negative for IgM, IgA, C3, C5/C9 complex and fibrinogen. Indirect immunofluorescence of the patient's serum was positive for elevated BP 180 antibodies to 39 (negative $<15$ ). She was treated with methotrexate $12.5 \mathrm{mg}$ weekly and prednisone $40 \mathrm{mg}$ daily. The prednisone was weaned over several months and the methotrexate was discontinued after 5 months. Her pain completely resolved after one week of therapy. She has been free from any lesions for nine months.

\section{Discussion}

Pemphigoid diseases, which include Bullous pemphigoid (BP) are autoimmune diseases clinically characterized by eruptive subepithelial pruritic bullae of the skin which can cause severe localized pain in the affected structure. BP is most prevalent in older adults (mean age greater than 80 years) and closely associated with less common mucous membrane pemphigoid ${ }^{[2-4]}$. The reports in the literature of BP associated with breast irradiation are sparse, however, when this condition arises, it may mimic many eruptive or infectious disease including streptococcal dermatologic infections which can be life threatening. With this is mind, careful evaluation and prompt management with accurate differential diagnosis is critical.

\subsection{Epidemiology}

It is a rare disease with incidence rates of 4 to 22 cases per million ${ }^{[5-7]}$ with a higher incidence in Pacific Rim countries; however it is considered the most common auto-immune disorder which causes blistering of the skin. The disease has a slight female predilection.

Pemphigoid disorders include bullous pemphigoid, myocutaneous pemphigoid, Brunsting-Perry pemphigoid, cicatricial pemphigoid, pemphigoid gestationis, and anti-laminin $\gamma 1$ pemphigoid and are characterized clinically by the presence of blistering, and/or eruptive muco-cutaneous lesions. Histologically, subepithelial cleavage and IgG and/or complement deposits at the epidermal basement membrane are noted. Closely associated, and in the differential diagnosis is pemphigus, which is identified microscopically by intraepidermal blister formation and antibody deposition within the actual epidermis.

\subsection{Pathogenesis}

The exact mechanism of injury of BP likely involves autoantibody-mediated injury of the epithelial basement membrane zone $^{[8,9]}$, specifically the hemidesmosome, which causes a typical inflammatory autoimmune cascade displacing the epidermis from the dermis resulting in the bullae and inflammatory local findings and named specifically for the disease: BP antigens 1 and $2^{[9]}$. Immunoglobulins are actively involved in the cascade, with IG 1 and IG 2 as minor contributors and IG 4 as the major antibody. Interestingly, IG 3 does not seem to be involved ${ }^{[10]}$. IgG and IgA basement membrane antibodies are associated with severe disease ${ }^{[11]}$. BP is classified as a Type 2 hypersensitivity disease. 
This antibody-mediated activation of the cascade by antibodies has been proposed as a mechanism for dermal lesion formation in $\mathrm{BP}^{[9,12]}$, and the presence of mast cells and eosinophils may act to worsen the clinical manifestation ${ }^{[13,14]}$.

Drug-induced forms of bullous pemphigoid have been reported in association with multiple medications such as furosemide, captopril, penicillamine, non-steroidal anti-inflammatory medications, and various antibiotics ${ }^{[15]}$. As auto immune diseases are sometimes triggered by drugs and infections, they may form a causative environment for pemphigoid as a result of cross-reactivity with antigens in the basement membrane. No infectious disorder has been definitively associated with pemphigoid; however, antibodies against hepatitis B, and C, Helicobacter pylori, Toxoplasmosis, and cytomegalovirus were more prevalent among patients with pemphigoid disease ${ }^{[16]}$.

Some diseases are also associated with BP, such as ocular pemphigoid in association with conjunctival inflammation due to Stevens-Johnson syndrome ${ }^{[7]}$ and lichen planus ${ }^{[17]}$.

Oral mucosal involvement occurs in 10 to 30 percent of patients with $\mathrm{BP}^{[18]}$.

\subsection{Therapeutic intervention}

In general, the morbidity related to BP generally results from indirect adverse effects of treatment or associated sequelae such as superinfections. Treatment is generally conservative in nature as early BP is uncommonly fatal and affected groups such as the elderly may not tolerate aggressive management. Elderly patients often have medical conditions that may increase risk for drug-related side effects. Thus, the minimal amount of medication required to achieve remission should be given.

Some clinicians advocate the daily rupturing of the bullae to reduce the lateral extension of the blister edges. However, the overlying epithelial layer of the bullae may provide a partial biologic shield and it is recommended (similar to patients with second degree burns) that the epithelium of the bullae be left intact after rupture to offer protection. First-line medical therapy for BP consists of topical corticosteroids such as clobetasol $0.05 \%$ cream, which is generally effective in mild cases $^{[5]}$. However in severe forms, systemic variants are necessary. Non-steroidal and other anti-inflammatory drugs may be effective as well, such as ibuprofen, tetracyclines (500 mg four times a day) administered with nicotinamide (500 $\mathrm{mg}$ three times a day) or dapsone ( $50-300 \mathrm{mg}$ daily). However, daily doses in excess of $200 \mathrm{mg}$ may cause hemolysis. For cases refractory or only partially responsive to steroids, immunomodulating drugs such as methotrexate $(2.5-5.0 \mathrm{mg} /$ week), mycophenolate mofetil and azathioprine can be highly effective. A course of up to 4 months may be necessary and a close follow up of potential serious drug related side effects in essential.

Recently, biologic therapies have shown efficacy in the management of refractory BP, such as rituximab $\left(375 \mathrm{mg} / \mathrm{m}^{2}\right.$ weekly $\times 4$ ), and intravenous immunoglobulin (IV IG) $2 \mathrm{~g} / \mathrm{kg}$ per cycle every four weeks ${ }^{[19,20]}$.

Overt subjective clinical improvement with lessening of the bullar size and decrease in the pain associated are important indicators of response. Reduction of erythema and the restoration of normal figurement will occur shortly after the initiation of effective therapy. Additionally, there are objective metrics of response. The level of BP180 antibodies in serum usually correlates with the clinical activity of BP ${ }^{[18]}$. Persistent elevated BP180 titer is a poor prognostic sign and may signify early relapse ${ }^{[21]}$. BP230 antibodies sometimes show a similar, but less pronounced response.

A minimum of two months following the disappearance of symptoms and signs is felt to be needed to ensure therapeutic success ${ }^{[22]}$. If relapse occurs, prompt reinstitution of therapy is suggested.

\subsection{Prognosis}

The clinical course of BP is highly variable and may result in a chronically recurrent representation ${ }^{[23-26]}$. Although BP is a potentially fatal disease, the exact mortality figures are unknown. Some authors describe estimates ranging from 11 to 48 
percent, while other find only a slight increase in mortality finding increased rates of mortality compared subjects without $\mathrm{BP}^{[7,17,27]}$. In one study, the most common causes of death were heart disease, infection, and neurologic disease ${ }^{[26]}$. Still others have found no significant difference. One retrospective study failed to find an increase in mortality compared to the general population ${ }^{[28]}$.

\section{Conclusions}

In patients who have undergone radiotherapy, only a few series have been published since the incidence of BP related to radiotherapy is small. Nevertheless, when bullous lesions are identified beyond the typical time frame of acute radiation sequelae, one should consider bullous pemphygoid as a serious condition with significant consequences including mortality. No routine screening exists for this disease which makes the need for clinical vigilance all the particularly important. Early intervention in BP yields complete and excellent results in most patients.

\section{References}

[1] CTCAE v 4.03. Available from:

http://dx.doi.org/evs.nci.nih.gov/ftp1/CTCAE/CTCAE_4.03_2010-06-14_QuickReference_5x7.pdf

[2] Keipert JA, Kelly R. Temporary Cushing's syndrome from percutaneous absorption of betamethasone 17-valerate. Med J Aust. 1971; 1: 542. PMid:4251769.

[3] Dreno B, Sassolas B, Lacour P, et al. Methylprednisolone versus prednisolone methylsulfobenzoate in pemphigoid: a comparative multicenter study. Ann Dermatol Venereol. 1993; 120: 518. PMid:8304707.

[4] Kirtschig G, Middleton P, Bennett C, et al. Interventions for bullous pemphigoid. Cochrane Database Syst Rev. 2010; CD002292. http://dx.doi.org/10.1002/14651858.cd002292.pub3

[5] Marazza G, Pham HC, Schärer L, et al. Incidence of bullous pemphigoid and pemphigus in Switzerland: a 2-year prospective study. Br J Dermatol. 2009; 161: 861. PMid:19566661. http://dx.doi.org/10.1111/j.1365-2133.2009.09300.x

[6] Schmidt E, della Torre R, Borradori L. Clinical features and practical diagnosis of bullous pemphigoid. Dermatol Clin. 2011; 29: 427. PMid:21605808. http://dx.doi.org/10.1016/j.det.2011.03.010

[7] Joly P, Baricault S, Sparsa A, et al. Incidence and mortality of bullous pemphigoid in France. J Invest Dermatol. 2012; 132: 1998. PMid:22418872. http://dx.doi.org/10.1038/jid.2012.35

[8] Kasperkiewicz M, Zillikens D, Schmidt E. Pemphigoid diseases: pathogenesis, diagnosis, and treatment. Autoimmunity. 2012; 45 : 55. PMid:21923615. http://dx.doi.org/10.3109/08916934.2011.606447

[9] Sagi L, Baum S, Agmon-Levin N, et al. Autoimmune bullous diseases the spectrum of infectious agent antibodies and review of the literature. Autoimmunity Rev. 2011; 10: 527. PMid:21527361. http://dx.doi.org/10.1016/j.autrev.2011.04.003

[10] Shirakata Y, Shiraishi S, Sayama K, et al. Subclass characteristics of IgG autoantibodies in bullous pemphigoid and pemphigus. J Dermatol. 1990; 17: 661. PMid:2094743. http://dx.doi.org/10.1111/j.1346-8138.1990.tb03008.x

[11] Oyama N, Setterfield JF, Powell AM, et al. Bullous pemphigoid antigen II (BP180) and its soluble extracellular domains are major autoantigens in mucous membrane pemphigoid: the pathogenic relevance to HLA class II alleles and disease severity. $\mathrm{Br} \mathrm{J}$ Dermatol. 2006; 154: 90. PMid:16403100. http://dx.doi.org/10.1111/j.1365-2133.2005.06998.x

[12] Liu Z, Giudice GJ, Swartz SJ, et al. The role of complement in experimental bullous pemphigoid. J Clin Invest. 1995; $95: 1539$. PMid:7706459. http://dx.doi.org/10.1172/JCI117826

[13] Dvorak AM, Mihm MC Jr, Osage JE, et al. Bullous pemphigoid, an ultrastructural study of the inflammatory response: eosinophil, basophil and mast cell granule changes in multiple biopsies from one patient. J Invest Dermatol. 1982; 78: 91. PMid:7035575. http://dx.doi.org/10.1111/1523-1747.ep12505711

[14] Goldstein SM, Wasserman SI, Wintroub BU. Mast cell and eosinophil mediated damage in bullous pemphigoid. Immunol Ser 1989; 46: 527. PMid:2484955.

[15] Bastuji-Garin S1, Joly P, Picard-Dahan C, et al. Drugs associated with bullous pemphigoid. A case-control study. Arch Dermatol. 1996 Mar; 132(3): 272-6. PMid:8607630. http://dx.doi.org/10.1001/archderm.1996.03890270044006

[16] Ahmed AR, Maize JC, Provost TT. Bullous pemphigoid. Clinical and immunologic follow-up after successful therapy. Arch Dermatol. 1977; 113: 1043. PMid:329769. http://dx.doi.org/10.1001/archderm.1977.01640080045002 
[17] Gual A, Mascaró JM Jr, Rojas-Farreras S, et al. Mortality of bullous pemphigoid in the first year after diagnosis: a retrospective study in a Spanish medical centre. J Eur Acad Dermatol Venereol. 2014; 28: 500. PMid:23279207. http://dx.doi.org/10.1111/jdv.12065

[18] Schmidt E, Obe K, Bröcker EB, et al. Serum levels of autoantibodies to BP180 correlate with disease activity in patients with bullous pemphigoid. Arch Dermatol. 2000; 136: 174. PMid:10677092. http://dx.doi.org/10.1001/archderm.136.2.174

[19] Wolina U, Koch A, Hansel G. Rituximab therapy of recalcitrant bullous dermatoses J Dermatol Case rep. 2008: 2(1): 4-7.

[20] Eskin-Schwartz M, David M, Mimouni D. Mycophenolate mofetil for the management of autoimmune bullous diseases. Dermatol Clin. 2011; 29: 555. PMid:21924997. http://dx.doi.org/10.1016/j.det.2011.06.012

[21] Bernard P, Reguiai Z, Tancrède-Bohin E, et al. Risk factors for relapse in patients with bullous pemphigoid in clinical remission: a multicenter, prospective, cohort study. Arch Dermatol. 2009; 145: 537. PMid:19451497. http://dx.doi.org/10.1001/archdermatol.2009.53

[22] Grundmann-Kollmann M, Korting HC, Behrens S, et al. Mycophenolate mofetil: a new therapeutic option in the treatment of blistering autoimmune diseases. J Am Acad Dermatol. 1999; 40: 957. http://dx.doi.org/10.1016/S0190-9622(99)70084-8

[23] Risser J, Lewis K, Weinstock MA. Mortality of bullous skin disorders from 1979 through 2002 in the United States. Arch Dermatol. 2009; 145: 1005. PMid:19770439. http://dx.doi.org/10.1001/archdermatol.2009.205

[24] Parker SR, Dyson S, Brisman S, et al. Mortality of bullous pemphigoid: an evaluation of 223 patients and comparison with the mortality in the general population in the United States. J Am Acad Dermatol. 2008; 59: 582. PMid:18707800. http://dx.doi.org/10.1016/j.jaad.2008.07.022

[25] Roujeau JC, Lok C, Bastuji-Garin S, et al. High risk of death in elderly patients with extensive bullous pemphigoid. Arch Dermatol. 1998; 134: 465. PMid:9554299. http://dx.doi.org/10.1001/archderm.134.4.465

[26] Cortés B, Marazza G, Naldi L, et al. Mortality of bullous pemphigoid in Switzerland: a prospective study. Br J Dermatol. 2011; 165: 368. PMid:21574978. http://dx.doi.org/10.1111/j.1365-2133.2011.10413.x

[27] Sokumbi O, el-Azhary RA, Langman LJ. Therapeutic dose monitoring of mycophenolate mofetil in dermatologic diseases. J Am Acad Dermatol. 2013; 68: 36. PMid:22884445. http://dx.doi.org/10.1016/j.jaad.2012.07.003

[28] Kwatra SG, Jorizzo JL. Bullous pemphigoid: a case series with emphasis on long-term remission off therapy. J Dermatolog Treat. 2013; 24: 327. PMid:22268701. http://dx.doi.org/10.3109/09546634.2012.660519 